\title{
Effect of the Training Program to Improve Emotional Creativity among Undergraduate Students
}

\author{
Ahmad M. Mahasneh, ${ }^{*}$ Ahmad M. Gazo \\ Department of Educational Psychology, Faculty of Educational Science, \\ The Hashemite University, Jordan \\ *Corresponding author. E-mail: dahmadmahasneh1975@yahoo.com
}

Background. The study of emotional creativity has not received very much attention in Arab studies. Emotional creativity is a clear concept that appears in the everyday practice of individuals.

Objective. The present study aimed to examine the effect of a training program on emotional creativity among undergraduate students.

Design. The study comprised 67 undergraduate students at the Hashemite University; the participants were divided between a control group $(\mathrm{N}=35)$, and an experimental group $(\mathrm{N}=32)$, and data was collected using the Emotional Creativity Inventory (ECI).

Results. The results showed that the training program was effective in improving participants' emotional creativity, and a statistically significant difference was found between the control and experimental groups, showing the effectiveness of the training program in favor of the experimental group. The researcher recommends that students begin to be trained in emotional creativity skills from an early age.

Conclusion. The results of data analysis in the current study document the impact of the training program in improving the level of emotional creativity among members of the experimental group. This may be due to the strategies and techniques used in the training program, which contributed to raising the level of emotional creativity.

Keywords: training program; creativity; emotional creativity; undergraduate students. 


\section{Introduction}

The concept of creativity has long been accepted as the aptitude to originate thoughts, perceptions, explanations, and resolutions, both novel and theoretically valuable (Amabile, 1996; Runco, 2004). The customary description of creativity denotes its duality by demanding novelty and innovation as well as efficacy (Kaufman \& Baer, 2012; Runco \& Jaeger, 2012). Characterizations of creativity are generally centered on the sphere of cognition (Williams, 1980), and the resolution of problems (Mumford, Mobley, Reiter-Palmon, Uhlman, \& Doares, 1991).

Averill and Nunley (1992) expanded the concept of creative expression to include the emotive characteristic, putting forward the proposition that the capacity to feel and communicate (i.e., emotional creativity) differs from one individual to another. Later, Averill, Chon, and Haan (2001) added that emotional transformations are themselves an expression of creativity, in which case the acquisition of emotional creativity benefits the individual's appreciation and enjoyment of life's pleasures, thereby leading to a more sensitive, aware, and gratifying life.

Since their research was published in 1980, Averill and his associates have focused on advancing awareness of the notion of emotional creativity from the standpoint of social-constructivism (Averill \& Nunley, 1992), thus creating a clear distinction between emotional creativity and emotional intelligence. Later studies (Averill, 2004; Ivcevic, Brackett, \& Mayer, 2007) carry a strong implication that emotional creativity could actually be taught, irrespective of natural ability.

In general, creative abilities are related to a wide range of variables along the spectrum of feelings and sentiments, particularly in regard to established constant emotional features. In their 1992 paper, Averill and Nunley propound the thesis that creativity is a state of mental activity, which combines all intelligent behaviors. Then Averill's 2005 study defined emotional creativity as a novel approach which extends an individual's thinking processes and improves relational interactivity, based on the following concepts: innovation, honesty, and effectiveness.

Innovation involves the ability to either change normal emotions into a novel emotive state distinctively unlike the normally accepted one, or to innovatively blend an individual's emotional norms. Effectiveness is the ability to adapt and harmonize creative responses to socially and culturally acceptable norms, thereby enabling the building of bonds and interactive relationships, and improving the individual's thought processes. Honest emotional expression signifies the origin or source of an emotion in the individual's personally-held views and principles (Manavipour, 2010). Averill (2005) expands these criteria and considers emotionally creative individuals to have the natural inclination and facility to devote more time to emotional recognition.

Emotional creativity therefore is a conceptual structure that facilitates the recognition and conceptual definition of emotions as either objectively or subjectively creative. In a further study Averill (2013) delineated four key emotional creativity criteria, founded on his concept of social constructivism:

1) Novelty: Novelty refers to an individual's ability to have a novel or different response from his/her previous behavioral reaction, or more generally, from usual societal reactions, and at the same time demonstrate relevance to current determinations. In this context it should also be mentioned that creativity is not limited to 
a small number of people, but since realization and achievement of new behavioral conduct is vital to human development, every individual must therefore possess some degree of creativity.

2) Effectiveness: In order to be creative, a reaction or response theoretically needs to benefit the individual, or a number of people. Therefore not all novel reactions are creative; on the contrary, some may in fact be peculiar and unhelpful.

3) Authenticity: The standards, ideals, morals, and principles embraced by an individual are reflected in a creative response and are, in fact, defined as tools.

4) Preparedness: Individuals go through a creative stage, which is of prime importance to the process of creativity, and may require long years of preparation before real creativity is achieved in a specific field (Ebrahimi, 2006).

Evaluation of individual levels of emotional creativity should be assessed by applying three criteria (e.g., effectiveness, modernization, and trust) to the individual's previous behavior. Given the assumption that the past predicts the future, preparedness can be a further indication of differences in individual creativity potential. To enable an individual to perform creatively in a particular field, it is imperative that he/she acquires the relevant knowledge, skill, and scientific understanding to do so (Jenaabadi, Marziyeh, \& Dadkan, 2015).

Ivcevic, Brackett, and Mayer (2007) define emotional creativity as the configuration of an individual's cognitive aptitudes and personality behaviors in relation to innovation, and his/her aptness in emotional responses; this encompasses, for example, simply applying an appropriate existing emotion, or a complex response in which the individual has to modify a customary emotion to meet current individual or group requirements (Averill, 1999). Ivcevic, Brackett, and Mayer (2007) also state that a key feature of emotional creativity includes the ability to deviate from the usual or commonplace, and originate innovative emotive reactions.

Gutbezahl and Averill (1996) had previously conceptualized the theory of emotional creativity within similar creativity constructs. Ivcevic, Brackett and Mayer (2007) commented on empirical research, which had studied the similarity and divergence of emotional creativity and emotional intelligence, including statistical and confirmatory factor analysis, which supported the division between emotional and cognitive creativity. This research confirmed that resolving emotional problems required the convergent thinking of emotional intelligence, whereas emotional creativity demanded divergent thinking in order to generate novel and apt responses. Research studies have found the dimensions of emotional creativity to correlate with feelings and attention, which is the emotional intelligence dimension. Similar results indicating this positive relationship have also been observed between the dimensions of effectiveness and authenticity of emotional creativity, and the clarity dimension of emotional intelligence, denoting the capability to clearly and appropriately differentiate individuals' moods.

Averill $(1999,2000)$ comments that comparisons between emotional and cognitive creativity are easily distinguished due to their use of diverse processes, although Davis (2009), and Runco and Jaeger (2012), point out that the two constructs do share a certain commonality, since both produce a creative reaction, either as an emotion or an idea generated on the basis of the common criteria of effectiveness and originality. In addition, Alfonso (2000) asser a positive association 
between a person's self-perception as having creative potential, and the conscious pursuit of creativity, both of which are positive adjuncts to creative results.

The small number of Arabic studies, which have researched emotional creativity, has focused on its association with cognitive memory, study skills, and academic interaction. The current study is aimed at examining the effects of a training program on emotional creativity among undergraduate students at the Hashemite University, and testing the following hypothesis:

\section{Hypothesis 1}

There are statistically significant differences in favor of the increased emotional creativity of the experimental group which underwent a training program, as compared to the control group.

\section{Methodology}

\section{Participants}

The study sample consisted of 67 students from the Faculty of Educational Science at the Hashemite University and was randomly divided into two groups, an experimental group comprising 32 students ( 9 male and 23 female), and a control group comprising 35 students (10 male and 25 female).The experimental group was exposed to the training program on emotional creativity while the control group was not exposed to any training program.

\section{Measures and Procedures}

Emotional Creativity Inventory (ECI): The emotional creativity inventory was developed by Averill (1999) and comprises 30 items. It consists of three subscales: 1) Novelty (14 items: e.g., "I can imagine myself being lonely, angry, and joyful, all at the same time"); 2) Preparedness (7 items: e.g., "I think about and try to understand my emotional reactions"), and 3) Authenticity/Effectiveness (9 items: e.g., "My emotions help me achieve my goals in life"). The respondents are asked to rate their agreement or disagreement with the statements based on a 5-point Likerttype scale ranging from $1=$ strongly disagree, to $5=$ strongly agree, with the higher scores on each of the three scales reflecting higher levels of emotional creativity. The Cronbach Alpha results were $(0.84,0.82$, and 0.83$)$ respectively for Novelty, Preparedness, and Authenticity/Effectiveness.

For the purposes of the current study, the authors have translated the emotional creativity inventory from English into Arabic; the translation was assessed by two qualified faculty members to ensure its integrity.

The Cronbach Alpha results were $(0.69,0.71$, and 0.68$)$ respectively for novelty, preparedness, and authenticity/effectiveness.

\section{Training Program}

To achieve the study objectives, we developed a training program in emotional creativity within the theoretical framework of the previous studies related to emotional creativity. We prepared training activities and training positions aimed at develop- 
Table 1

Training program content and goals

\begin{tabular}{cccc}
\hline $\begin{array}{c}\text { Session } \\
\text { no }\end{array}$ & Title & Session content and goals & Time \\
\hline
\end{tabular}

1. Introduction

2. Definition of the training program

3. Emotion

4. Perceiving emotions

5. Understanding emotions

6. Importance of emotions

7. Regulation of emotions

8. Thinking about emotions

9. Emotional response

10. Expression of emotions

11. Attention to emotions

12. Emotional experience

13. Causes of emotions

14. Development of emotions

15. Diversity of emotional response

16. Relevance of emotional response

17. Control of emotions

18. Discrimination of emotions
The session aimed to acquaint the students and researcher, and define the general and special objectives of the training program.

The session aimed at the definition of emotional creativity concept, and get students to recognize the importance of the training program and component.

The session aimed to identify and describe a feeling associated with an emotion.

The session aimed to develop students' abilities to identify their own emotions and the emotions of others.

The session aimed to train students to understand emotional information, understand emotions' meaning, and relationships between emotions.

The session aimed to train students in understanding the importance of emotions in daily life.

The session aimed to train students to recognize emotions and feelings, and understand how emotions affect others' behavior.

The session aimed to train students to think about their emotions before having emotional reactions.

The session aimed to train students to emotionally respond in new ways.

The session aimed to train students to express emotions which help them establish relationships with other people, and express emotions in a verbal and non-verbal manner.

The session aimed to train students to be aware of their emotions, and pay attention to emotions of others in order to understand their own emotions better.

The session aimed to train students to meditate on their previous emotional experiences and to benefit from them in their current emotional experience.

The session aimed to train students to understand the causes of their emotions and those of the emotions of others.

The session aimed to train students to develop their 50 minutes emotions in effective ways.

The session aimed to train students to demonstrate nontraditional emotional responses and show varied emotional responses.

The session aimed to train students to show appropriate 50 minutes emotional responses to different situations.

The session aimed to train students to control their 50 minutes emotional reactions.

The session aimed to train students to distinguish be- 50 minutes tween real and unreal emotions.
50 minutes

50 minutes

50 minutes

50 minutes

50 minutes

50 minutes

50 minutes

50 minutes

50 minutes

50 minutes

50 minutes

50 minutes

50 minutes

50 minutes 
ing students' emotional creativity skills according to the followings steps: 1) Define the skills of emotional creativity (novelty, preparedness, authenticity/ effectiveness) targeted in the training program; 2) Implement the training using the following methods: discussion, divergent thinking, activities, small-group work, role playing, feedback, giving examples, reading story, and brainstorming; and 3) Have researchers train the students in the experimental group on the skills in three training sessions per week, according to the procedures and steps outlined above.

The training program was designed for the purposes of the current study, in accordance with the dimensions of emotional creativity, which include the areas of novelty, preparedness, and authenticity/effectiveness. The program consisted of 18 sessions, and it was carried out over the period between Oct. 15, 2017 and Dec. 5, 2017) at a rate of three sessions per week; each session was assigned fifty minutes. The contents of the training program are described in Table 1.

\section{Data Collection and Analysis}

Before and after completing the training program with the experimental group, the Emotional Creativity Inventory (ECI) was distributed to participants in both the experimental and control groups. Data were entered and processed using SPSS (V.20). To achieve the study objectives, means, standard deviations, and independent sample t-tests were used to ensure equivalency between the control and experimental groups. Analysis of covariance (ANCOVA) was used to compare the control and experimental groups on emotional creativity at the end of the training program.

\section{Results}

To ensure equivalency between the control and experimental groups, the Emotional Creativity Inventory was administered to all participants. The means and standard deviations were calculated, and the independent sample t-test was used to find differences in emotional creativity, as shown in Table 2.

Table 2

Results of independent $t$-tests regarding comparison of students' emotional creativity before treatment

\begin{tabular}{llllllll}
\hline \multicolumn{1}{c}{ Variables } & Group & N & M & SD & df & T & sig \\
\hline Novelty & Control & 35 & 2.98 & 0.71 & 65 & 0.185 & 0.85 \\
& Experimental & 32 & 2.95 & 0.60 & & & \\
Preparedness & Control & 35 & 2.89 & 0.82 & 65 & 0.686 & 0.49 \\
& Experimental & 32 & 2.76 & 0.77 & & & \\
Authenticity/ & Control & 35 & 2.98 & 0.67 & 65 & -0.099 & 0.92 \\
Effectiveness & Experimental & 32 & 3.00 & 0.66 & & & \\
Emotional & Control & 35 & 2.95 & 0.59 & 65 & 0.346 & 0.73 \\
creativity & Experimental & 32 & 2.90 & 0.56 & & & \\
\hline
\end{tabular}


The level of emotional creativity among control and experimental groups before treatment as shown in Figure 1.

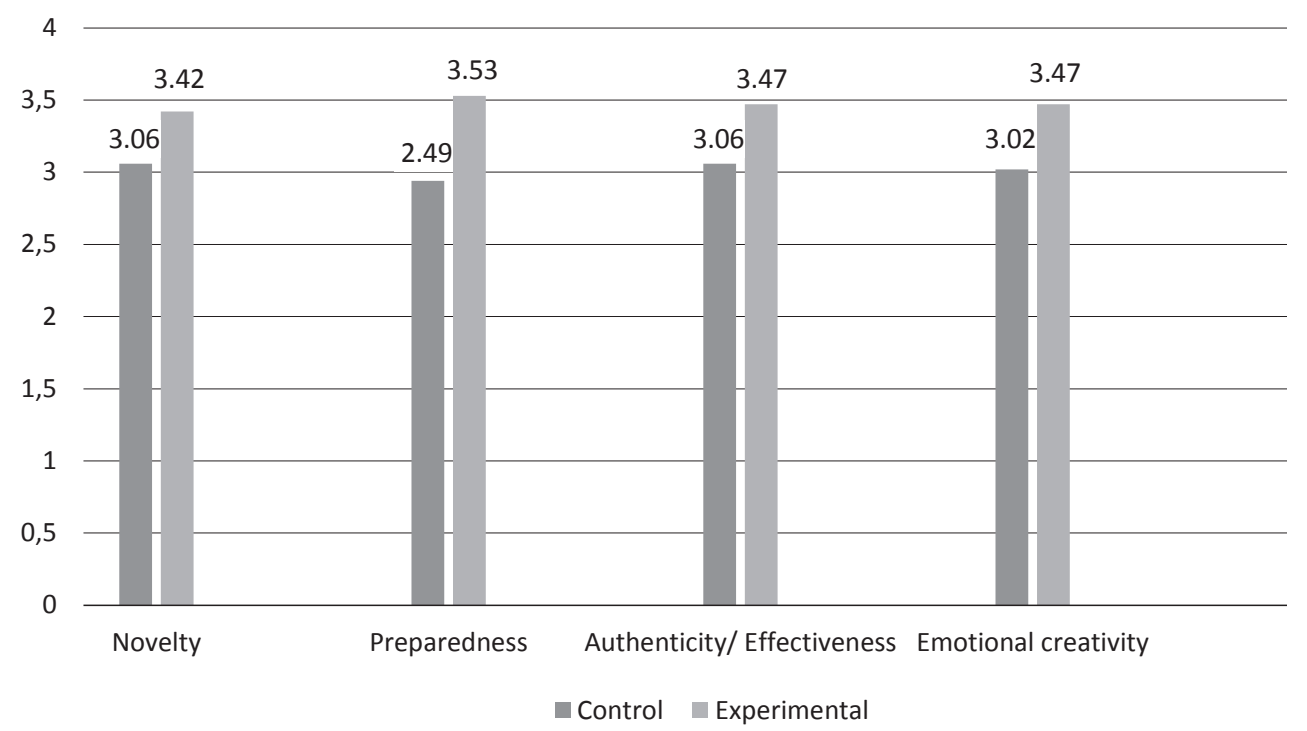

Figure 1. Levels of emotional creativity before treatment

Table 2 shows no statistical differences between control and experimental groups in levels of emotional creativity. The t-test values were not significant at the 0.05 level. This result indicates control and experimental group equivalence in the level of emotional creativity.

Hypothesis 1: There are statistically significant differences in favor of the increased emotional creativity of the experimental group which underwent a training program, as compared to the control group.

Means and standard deviations of the students' emotional creativity scores on the post-test were calculated. Table 3 presents the values.

Table 3

Means and standard deviation for the results of the students' emotional creativity test after treatment

\begin{tabular}{lllcc}
\hline \multicolumn{1}{c}{ Variables } & \multicolumn{1}{c}{ Group } & N & Means & S.D \\
\hline Novelty & Control & 35 & 3.06 & 0.63 \\
& Experimental & 32 & 3.42 & 0.42 \\
\hline \multirow{2}{*}{ Preparedness } & Control & 35 & 2.94 & 0.68 \\
& Experimental & 32 & 3.53 & 0.34 \\
& Control & 35 & 3.06 & 0.38 \\
Authenticity/ & Experimental & 32 & 3.47 & 0.28 \\
Effectiveness & Control & 35 & 3.02 & 0.45 \\
Emotional & Experimental & 32 & 3.47 & 0.23 \\
\hline creativity & & & & \\
\hline
\end{tabular}


The level of emotional creativity among control and experimental groups after treatment as shown in Figure 2.

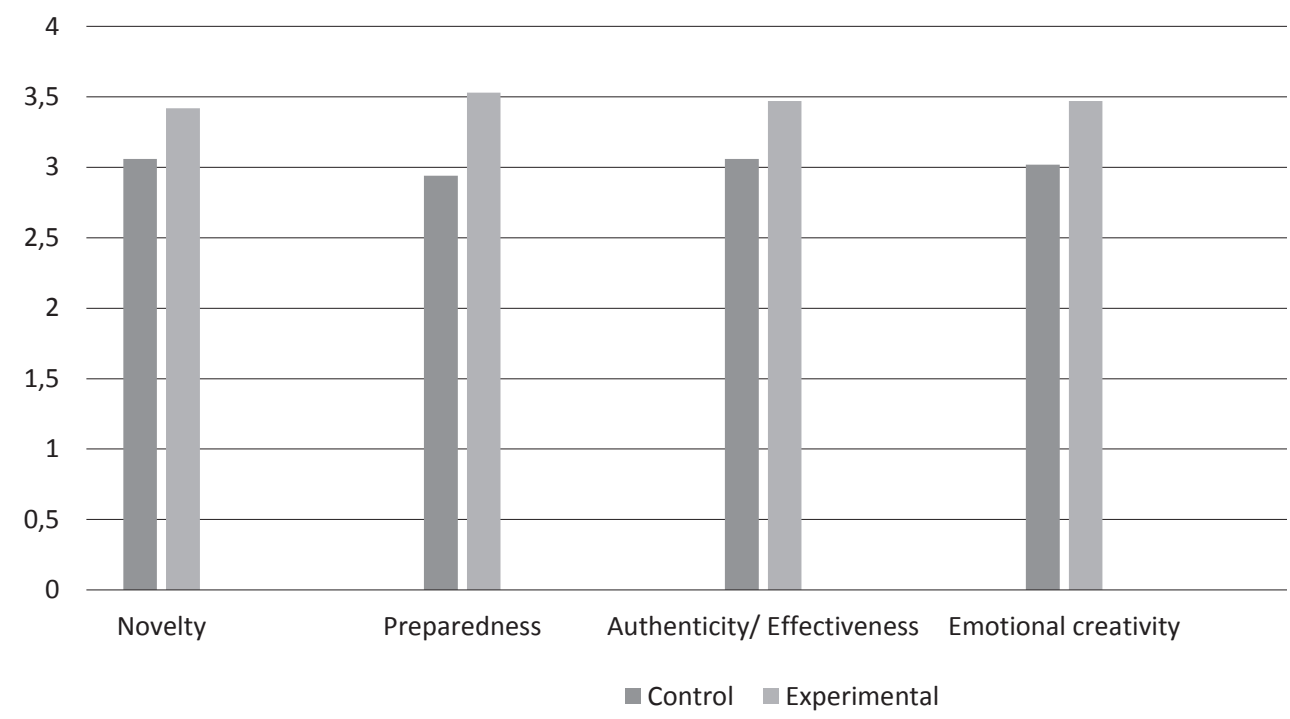

Figure 2. Levels of emotional creativity after treatment

Table 4

ANCOVA determining the significance of the differences between the control group and the experimental group in emotional creativity scores

\begin{tabular}{lcccccc}
\hline \multicolumn{1}{c}{ Source } & $\begin{array}{c}\text { Sum of } \\
\text { squares }\end{array}$ & Df & $\begin{array}{c}\text { Means } \\
\text { square }\end{array}$ & F & Sig. & $\begin{array}{c}\text { Partial Eta } \\
\text { squared }\end{array}$ \\
\hline Novelty & 6.183 & 1 & 6.183 & 29.516 & 0.00 & .31 \\
Method & 2.318 & 1 & 2.318 & 11.065 & 0.00 & .14 \\
Error & 13.406 & 64 & & & & \\
Corrected total & 21.737 & 66 & 0.209 & & & \\
Preparedness & 6.120 & 1 & 6.120 & 29.314 & 0.00 & .31 \\
Method & 6.709 & 1 & 6.709 & 32.132 & 0.00 & .33 \\
Error & 13.362 & 64 & 0.209 & & & \\
Corrected total & 25.190 & 66 & & & & \\
Authenticity/ Effectiveness & 1.007 & 1 & 1.007 & 9.696 & 0.00 & .13 \\
Method & 2.760 & 1 & 2.760 & 26.586 & 0.00 & .29 \\
Error & 6.644 & 64 & & & & \\
Corrected total & 10.452 & 66 & 0.104 & & & \\
Emotional creativity & 3.418 & 1 & 3.418 & 41.060 & 0.00 & .39 \\
Method & 3.688 & 1 & 3.688 & 44.309 & 0.00 & .40 \\
Error & 5.328 & 64 & & & & \\
Corrected total & 12.141 & 66 & 0.083 & & & \\
\hline
\end{tabular}

${ }^{*}$ Statistical Significance Level of 0.05 
Table 3 shows that there are statistical differences between the control and experimental groups in the level of emotional creativity after the end of the training program. The mean post-test scores for novelty were: control group $=3.06$, experimental group $=3.42$; the mean post-test scores for preparedness were: control group $=2.94$, experimental group $=3.53$; the mean post-test score for authenticity/ effectiveness were: control group $=3.06$, experimental group $=3.47$; and the mean post-test scores for emotional creativity were: control group $=3.02$, experimental group $=3.47$. To determine the significance of the differences, ANCOVA was conducted. Table 4 presents the values.

Table 4 shows that there are statistically significant differences in the students' emotional creativity post-test between the control and experimental groups on all strategies attributed to the training program, in favor of the experimental group. More specifically, novelty explained $31 \%$ of variance in emotional creativity; preparedness explained $22 \%$ of variance in emotional creativity; authenticity/effectiveness explained $13 \%$ in emotional creativity.

\section{Discussion}

The results of the current study revealed that students who underwent training scored higher in emotional creativity than those who did not. As reported before, the mean scores for novelty were control group $=3.06$, experimental group $=3.42$; the mean scores for preparedness were control group $=2.94$, experimental group $=3.53$; the mean scores for authenticity/effectiveness were control group $=3.06$, experimental group $=3.47$; and the mean scores for emotional creativity were control group $=3.02$, experimental group $=3.47$.

These results can be explained in the light of the training program contents and the components of the program sessions. The training methods encouraged participation and involvement in discussion, role-playing, imagination, and molding, which contributed to increasing the motivation of students to benefit from the program.

The successful results may also be explained by the comfortable psychological atmosphere of the training session, the full freedom to think and express opinions, respect for individual differences, and openness to new experiences that combined to develop the self-confidence of the students participating in the training program. Perhaps this contributed to the interaction of students in training activities and their participation was effective in discussing problems and developing appropriate solutions. The consistent dimensions of the training program (novelty, preparedness and authenticity/effectiveness), have also contributed to the improvement of students' emotional creativity.

As to the first dimension, novelty, students were trained to show different and unique emotional reactions, imagine positive and negative emotions at the same time, respond uniquely to emotional situations, imagine situations calling for nontraditional emotional reactions, and explore a variety of emotional reactions, all of which increased the ability of the experimental group students to create novel responses. As to the second dimension, preparedness, students were trained to search for reasons that provoke individuals' strong emotional reactions, to work on emotional development, understand emotional reactions, and be fully aware 
of the emotional aspects of their lives, thereby increasing preparedness among the students of the experimental group. As to the third dimension, authenticity/ effectiveness, students were trained to respond well in situations that require new and unusual emotional responses, a good expression of emotions, achievement of life goals by emotions, and emotional reactions truly reflecting their thoughts and feelings, which increased the authenticity/effectiveness among the students of the experimental group.

Up until now, all the investigations into creativity training have focused on the cognitive aspect (Ma, 2006; Scott, Leritz, \& Mumford, 2004). Experimental studies in the field of emotional creativity training are rare, although a proposal by Averill (1999) suggested participation in dramatic performance as a potential aid in increasing emotional creativity. In their study of trainee teachers who took emotional creativity courses pre-service and in-service, Singh and Kumar (2010) found a higher level of emotional creativity among those who took the training program in-service. The results of the current study differ from the results of a study by Dyson et al. (2016), which showed that there was no effect of tabletop role-playing games on emotional creativity among Taiwanese college students.

A significant in-depth analysis of 70 emotional creativity training studies covering a wide range of diverse approaches was undertaken by Scott, Leritz, and Mumford (2004). Their results demonstrate that not only is it possible to teach cognitive creativity, but also that the most effective results were achieved using divergent thinking and problem-solving methods. Averill (1999) conjectures that since the use of divergent thinking was found to be highly effective, individuals' creativity levels may well be increased by using drama and acting methods as a training technique.

Given the similarity of commonly used creativity training methods, there is a need for trainers themselves to use their imaginative and creative skills to explore and create novel and effective ways of improving creativity. Recognizing the need to inspire student interest, a few studies (Dziedziewicz, Oledzka, \& Karwowski, 2013; Dziedziewicz, Gajda, \& Karwowski, 2014), used innovative methods to construct appropriate activities with the aim of inspiring student curiosity and interest; in addition, they used the important novel concept of the doodle-book, and at the same time introduce intercultural competence training, thus contributing to enhancing learner creativity.

Frolova (2016) proposes that there is now acceptance and confirmation of the positive effect that emotional creativity has on optimizing individual potential and merits, which results in the ability to adapt both psychologically and socially. Controlling emotions both flexibly and creatively provides a coping mechanism for handling anxiety and reducing exaggerated reflex reactions to the normal stresses and strains of daily life. The ability to swiftly change an automatic strongly emotional negative reaction and replace it with a more constructive emotional response serves a dual beneficial purpose, by exerting a calming and steadying influence and thereby diminishing the likelihood of impulsive violence.

Developing emotional creativity improves self-confidence and creates an optimistic outlook, which increases resistance to the damaging effects of stress. An essential criterion for effective anger management is acquiring the ability to rapidly convert a stereotypical negative emotional reaction into a positive response, which 
protects the individual against the exhausting and damaging effects of mental stress. Developing the ability to quickly convert stereotypically arising negative emotions is a prerequisite to good anger management and serves to prevent mental exhaustion.

The university should give greater attention to the activities of talented and creative students in various fields because these students are future leaders. And it should provide all students the opportunity to develop their creativity and give them an atmosphere of freedom for thinking and experimentation.

Based on the results of the current study, we recommend that students be trained in emotional creativity skills starting at an early age. The current study was limited to undergraduate student in the faculty of educational science. Future studies should involve students at the elementary school or high school level. Future studies can also focus on the effects of training program-based problem solving on improving emotional creativity.

\section{Conclusion}

The results of data analysis in the current study demonstrate the impact of the training program in improving the level of emotional creativity among members of the experimental group. This may be due to the strategies and techniques used in the training program which contributed to raising the level of emotional creativity.

\section{References}

Alfonso, V. (2000). An analysis of the interaction between the cognitive and affective-personal components in the creative process. Unpublished Master's Thesis, University of Madrid, Spain.

Amabile, T.M. (1996). Creativity in Context. Colorado: West view Press. http://dx.doi.org/10.4324/9780429501234

Averill, J.R. (1980). A constructivist view of emotion. In R. Plutchik \& H. Kellerman (Eds.), Emotion: Theory, research and experience, vol. 1 (pp. 305-339). New York: Academic Press. http://dx.doi.org/10.1016/B978-0-12-558701-3.50018-1

Averill, J.R. (1999). Individual differences in emotional creativity: Structure and correlates. Journal of Personality, 67(2), 331-371.

Averill, J.R. (2000). Intelligence, emotion and creativity: From tracheotomy to trinity. In R. Bar-On \& D.A. Parker (Eds.), Handbook of emotional intelligence (pp. 277-298). San Francisco, CA: JossBass.

Averill, J.R. (2004). Emotions as mediators and as products of creative activity. In J. Kaufman \& J. Baer (Eds.), Faces of the muse: how people think, work and act creatively in diverse domains. Mahwah, NJ: Lawrence Erlbaum Associates, Inc.

Averill, J.R. (2005). Emotions as mediators and as products of creative activity. In J. Kaufman \& J. Baer (Eds.), Creativity across domains: Faces of the muse (pp. 225-243). Mahwah, NJ: Erlbaum.

Averill, J. (2013). Individual Differences in Emotional Creativity: Structure and Correlates. Journal of Personality, 67, 331-371.

Averill, J.R., Chon, K.K., \& Haan, D.W. (2001). Emotions and creativity, East and West. Asian Journal of Social Psychology, 4, 165-183. http://dx.doi.org/10.1111/1467-839X.00084

Averill, J.R., \& Nunley, E.P. (1992). Voyages of the heart: Living an emotionally creative life. New York: Free Press.

Davis, M. (2009). Understanding the relationship between mood and creativity: A meta-analysis. Organizational Behavior and Human Decision Processes, 108, 25-38. 
Dyson, S., Chang , Y., Chen, H., Hsiung, H., Tseng, C., \& Chang, J. (2016). The effect of tabletop roleplaying games on the creative potential and emotional creativity of Taiwanese college students. Thinking Skills and Creativity, 19, 88-96. http://dx.doi.org/10.1016/j.tsc.2015.10.004

Dziedziewicz, D., Oledzka, D., \& Karwowski, M. (2013). Developing 4- to 6-year-old children's figural creativity using a doodle-book program. Thinking Skills and Creativity, 9, 85-95.

Dziedziewicz, D., Gajda, A., \& Karwowski, M. (2014).Developing children's intercultural competence and creativity. Thinking Skills and Creativity, 13, 32-42.

Ebrahimi, E. (2006). Comparing and Investigating the Relationship of Styles of Coping with Mental Stress, Emotional Creativity and Mental Health of Athlete and Non-Athlete University Students. Master's Thesis, Tehran Teacher Training University, Iran.

Frolova, S.V. (2016). Training of emotional creativity and development of adaptive personal qualities. International Annual Edition of Applied Psychology: Theory, Research and Practice, 3(1), 78-85.

Gutbezahl, J., \& Averill, J.R. (1996). Individual Differences in Emotional creativity as manifested in words and pictures. Creativity Research Journal, 9, 237-337. http://dx.doi.org/10.1207/ s15326934crj0904_4

Jenaabadi, H., Marziyeh, A., \& Dadkan, A.M. (2015). Comparing Emotional Creativity and Social Adjustment of Gifted and Normal Students. Advances in Applied Sociology, 5, 111-118. http://dx.doi.org/10.4236/aasoci.2015.53010

Ivcevic, Z., Brackett, M.A., \& Mayer, J.D. (2007). Emotional intelligence and emotional creativity. Journal of Personality, 75, 199-236. http://dx.doi.org/10.1111/j.1467-6494.2006.00437.x

Kaufman, J.C., \& Baer, J. (2012). Beyond new and appropriate: Who decides what is creative? Creativity Research Journal, 24, 83-91.

Ma, H.H. (2006). A synthetic analysis of the effectiveness of single components and packages in creativity training programs. Creativity Research Journal, 18, 435-446. http://dx.doi.org/10.1207/ s15326934crj1804_3

Manavipour, D. (2010). Relation between emotional creativity and cognitive creativity with metacognitive skills. Journal of psychological researches, 2, 63-72.

Mumford, M.D., Mobley, M.I., Reiter-Palmon, R., Uhlman, C.E., \& Doares, L.M. (1991). Process Analytic Models of Creative Capacities. Creativity Research Journal, 4(2), 91-122. http://dx.doi. org/10.1080/10400419109534380

Runco, M.A. (2004). Creativity. Annual Review of Psychology, 55,657-687.

Runco, M.A., \& Jaeger, G.J. (2012). The standard definition of creativity. Creativity Research Journal, 24, 92-96. http://dx.doi.org/10.1080/10400419.2012.650092

Singh, G., \& Kumar, G. (2010). Emotional creativity among pre-service and in-service trainee teachers. IManagers Journal on Educational Psychology, 4(1),33-36. http://dx.doi.org/10.26634/jpsy.4.1.1221

Scott, G., Leritz, L.E., \& Mumford, M.D. (2004). The effectiveness of creativity training: a quantitative review. Creativity Research Journal, 16, 361-388.

Williams, F.E. (1980). The creativity assessment packet. Chesterfield, MO: Psychologists and Educators Inc.

Original manuscript received October 24, 2018

Revised manuscript accepted June 24, 2019

First published online September 30, 2019

To cite this article: Mahasneh, A.M., Gazo, A.M. (2019). Effect of the Training Program to Improve Emotional Creativity among Undergraduate Students. Psychology in Russia: State of the Art, 12(3), 137-148. DOI: 10.11621/pir.2019.0310 